\title{
Associations between herd-level factors and lying behavior of freestall-housed dairy cows
}

\author{
K. Ito, ${ }^{\star} \dagger$ N. Chapinal, ${ }^{*}$ D. M. Weary, ${ }^{\star}$ and M. A. G. von Keyserlingk ${ }^{* 1}$ \\ *Animal Welfare Program, University of British Columbia, Vancouver, BC V6T 1Z4, Canada \\ †Novus International Inc., St. Charles, MO 63304
}

\begin{abstract}
Our objective was to investigate the associations between herd-level factors and lying behavior of highproducing dairy cows housed in freestall barns. Lying behavior of approximately 40 focal cows in one highproducing pen was monitored on each of 40 farms in the northeastern United States (NE) and 39 farms in California (CA). All cows within the pen were gait scored using a 1-to-5 scale to calculate the prevalence of clinical lameness (score $\geq 3$ ) and severe lameness (score $\geq 4$ ). Facility and management measures, including stall design, bedding, and flooring type within the pen, were collected. Herd-level factors associated with daily lying time, standard deviation (SD) of daily lying time, frequency of lying bouts, and lying bout duration at the univariate level were submitted to multivariable general linear models. In the NE, daily lying time increased with the use of deep bedding (estimate $=0.80 \pm 0.31$ $\mathrm{h} / \mathrm{d}$ ) and as average days in milk (DIM) of the focal cows increased (estimate $=0.08 \pm 0.04 \mathrm{~h} / \mathrm{d}$ for a $10-\mathrm{d}$ increase in DIM). The SD of daily lying time decreased as stall stocking density increased (estimate $=-0.08$ $\pm 0.03 \mathrm{~h} / \mathrm{d}$ for a $10 \%$ increase), and increased with the presence of rubber flooring in the pen (estimate $=0.16 \pm 0.08 \mathrm{~h} / \mathrm{d}$ ) and percentage of stalls with fecal contamination (estimate $=0.04 \pm 0.01 \mathrm{~h} / \mathrm{d}$ for a $10 \%$ increase). Frequency of lying bouts decreased (estimate $=-1.90 \pm 0.63$ bouts $/ \mathrm{d}$ ) and average bout duration increased (estimate $=15.44 \pm 3.02 \mathrm{~min}$ ) with the use of deep bedding. In CA, where all farms used deep bedding, daily lying time increased as average DIM of the focal cows increased (estimate $=0.08 \pm 0.03 \mathrm{~h} / \mathrm{d}$ for a 10-d increase). The SD of daily lying time decreased when feed was delivered more than once per day (estimate $=-0.24 \pm 0.08 \mathrm{~h} / \mathrm{d}$ ). The percentage of lame cows was correlated with the percentage of stalls with fecal contamination $(\mathrm{r}=0.45)$, which in turn was associated with fewer (estimate $=-0.25 \pm 0.06$ bouts $/$ d)
\end{abstract}

Received March 28, 2013.

Accepted December 7, 2013.

${ }^{1}$ Corresponding author: marina.vonkeyserlingk@ubc.ca and longer lying bouts (estimate $=1.85 \pm 0.39 \mathrm{~min} / \mathrm{d}$ ) . These findings suggest that lying time be interpreted in conjunction with variability in lying time and bout structure and in context with lameness prevalence, production parameters, and facility characteristics.

Key words: cow comfort, deep bedding, management, stall design

\section{INTRODUCTION}

Lying behavior, particularly the time spent lying down, the frequency of lying bouts (i.e., a transition from standing to lying), and the duration of individual bouts can be used to assess the quality of the lying area (Haley et al., 2000). For example, cows spend more time lying down and have a higher frequency of lying bouts on mattresses or rubber mats compared with concrete lying surfaces (Haley et al., 2001; Rushen et al., 2007), and on deep bedding versus poorly bedded mattresses (Tucker et al., 2003). Similarly, cows spend more time lying down and have longer bouts in wider stalls (Tucker et al., 2004) and on deep-bedded sand stalls compared with mattresses (Gomez and Cook, 2010). Lying time also responds to changes in management and environmental conditions. For example, lying time increased from 11.4 to $13.7 \mathrm{~h} / \mathrm{d}$ when deep-bedded sand stalls were consistently maintained versus stalls with the sand dug out $6.2 \mathrm{~cm}$ below the curb (Drissler et al., 2005). Lying time decreased by $1.7 \mathrm{~h} / \mathrm{d}$ when the stocking density (number of cows per stall) increased from 100 to $150 \%$ (Fregonesi et al., 2007), and was reduced by as much as $3 \mathrm{~h} / \mathrm{d}$ when the temperature-humidity index (THI) in the barn exceeded 72 for more than 10 h/d (Cook et al., 2007).

Lying behavior is also influenced by the health and production status of the cow. For instance, lame cows have increased lying times and longer lying bouts (Chapinal et al., 2009; Ito et al., 2010), although changes in lying behavior by lame cows depend on the type of stall surface, time available for lying down, and stall standing activity (Gomez and Cook, 2010). In contrast, cows with clinical mastitis spend more time standing, suggesting discomfort while lying down (Cyples et al., 
2012). Among healthy cows, daily lying time increases as DIM increases (Endres and Barberg, 2007; Bewley et al., 2010; Vasseur et al., 2012) and is lower for cows producing more milk (Fregonesi and Leaver, 2001; Norring et al., 2012), likely because of the increased time spent feeding by high-yielding cows.

Previous research has shown that dairy cows in tie-stalls are motivated to maintain approximately 12 $\mathrm{h} / \mathrm{d}$ of lying time (Jensen et al., 2005). Lying down is a higher priority behavior compared with feeding or social contact (Munksgaard et al., 2005), and chronic lying deprivation is physiologically harmful as demonstrated by heightened hypothalamic-pituitary-adrenal activity (Munksgaard and Simonsen, 1996). Lying may also facilitate recovery from illness (Hart, 1988; Johnson, 2002). Average lying times of approximately 12 to 13 h/d (e.g., Drissler et al., 2005; Fregonesi et al., 2007; Gomez and Cook, 2010) are now widely accepted as the target for lactating dairy cows in freestall facilities (NFACC, 2009). However, cross-sectional studies on commercial dairy farms across North America found that average lying times among high-producing cows were 10 to $11 \mathrm{~h} / \mathrm{d}$, with few farms having an average lying time over 12 h/d (Ito et al., 2009; von Keyserlingk et al., 2012). These studies have also found more variation in lying behavior among individual cows within farms than across farms (Ito et al., 2009).

Lying behavior in commercial settings is likely influenced by a combination of factors, such as management, facility design, and the prevalence of lameness. However, most research to date has focused on cowlevel factors, such as lameness status (Ito et al., 2010) or DIM (Bewley et al., 2010), and characteristics of the lying surface (Tucker and Weary, 2004), and has primarily been conducted either in controlled settings or on a limited number of commercial farms within a certain region. The objective of this study was to undertake a comprehensive investigation of the associations between herd-level factors such as the prevalence of lameness, management and facility design, and different lying behavior measures (including measures of variability within farm) in high-producing dairy cows on freestall commercial farms in the northeastern United States and California. These 2 regions were selected because of their differences in the prevalence of lameness, management, and facility design (see von Keyserlingk et al., 2012).

\section{MATERIALS AND METHODS}

\section{Farm Selection and Visits}

A total of 40 farms in the northeastern United States $(\mathbf{N E} ; \mathrm{n}=28$ in New York, $\mathrm{n}=8$ in Pennsylvania, and $\mathrm{n}=4$ in Vermont), and 39 farms in California (CA) were selected within the Novus C.O.W.S. program, a partnership between The University of British Columbia and Novus International Inc. (http://www.novusint. com/en/Market-Segments/Dairy/COWS), for this cross-sectional study. Consulting nutritionists $(\mathrm{n}=24$ in $\mathrm{NE} ; \mathrm{n}=8$ in $\mathrm{CA}$ ) were asked to select farms considering 2 inclusion criteria: freestall housing and TMR feeding. Nutritionists were asked to randomly identify dairies that met the criteria and were willing to participate in the study. The farms $(\mathrm{n}=79)$ included in this study made up a portion of the farms described in von Keyserlingk et al. (2012), which presented descriptive analyses regarding facility design, lying behavior, skin injuries, and lameness of 121 freestall farms located in 3 different regions of North America. The farms used in the current study are also the same farms described by Chapinal et al. (2013) and Barrientos et al. (2013), which focused on identifying facility and management risk factors for lameness and hock injuries, respectively. This current study describes the associations between herd-level factors and lying behavior of freestall-housed dairy cows, which has not yet been reported and, to our knowledge, will make use of the most comprehensive data set available to date. The University of British Columbia's Animal Care Committee, following the standards of CCAC (2009), approved all animal-based measures.

Farms were visited between March and May 2010 in CA, and between July and October 2010 in NE. The same 2 trained observers visited each farm twice, with approximately 3 to $5 \mathrm{~d}$ between visits, collecting a range of measures (Table 1). The group with the highest milk production and consisting of primarily multiparous cows was assessed on each farm (assessment group).

\section{Animal-Based Measures}

Lying Behavior. From the assessment group, 40 cows were systematically selected as "focal cows" based on the number of units in the milking parlor. For example, if the parlor had 20 units and the group had 100 cows, 8 cows per rotation were selected (to have a final sample size of 40 cows). This systematic selection was done to remove any effect of milking order, as previous work has shown an association between order of milking and lameness (e.g., Main et al., 2010). The sample size was decided based on Ito et al. (2009), who found reliable estimates of lying behavior on commercial dairy farms using at least $3 \mathrm{~d}$ of continuous recordings (at 1-min intervals) from at least 30 focal cows per group. Lying behavior was recorded using electronic data loggers (Hobo Pendant G Acceleration Data Loggers, Onset Computer Corp., Pocasset, MA) at 1-min intervals for $3 \mathrm{~d}(72 \mathrm{~h})$, as validated by Ledgerwood et 
Table 1. Predictors considered in the univariable analysis for each region (northeastern United States, NE, and California, CA)

\begin{tabular}{|c|c|c|}
\hline Predictor & Unit/category $^{1}$ & Region \\
\hline \multicolumn{3}{|l|}{ Animal-based measures } \\
\hline Lactation number ${ }^{2}$ & no. & $\mathrm{NE}, \mathrm{CA}$ \\
\hline $\mathrm{DIM}^{2}$ & $\mathrm{~d}$ & $\mathrm{NE}, \mathrm{CA}$ \\
\hline Percentage of clinically lame cows ${ }^{3}$ & $\%$ & $\mathrm{NE}, \mathrm{CA}$ \\
\hline Percentage of severely lame cows ${ }^{3}$ & $\%$ & $\mathrm{NE}, \mathrm{CA}$ \\
\hline \multicolumn{3}{|l|}{ General management } \\
\hline Herd size & no. & $\mathrm{NE}, \mathrm{CA}$ \\
\hline Barn age & $\mathrm{yr}$ & $\mathrm{NE}, \mathrm{CA}$ \\
\hline Temperature-humidity index ${ }^{4}$ & - & $\mathrm{NE}, \mathrm{CA}$ \\
\hline \multicolumn{3}{|l|}{ 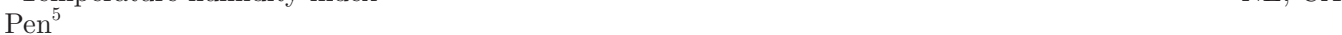 } \\
\hline Space & $\mathrm{m}^{2} / \mathrm{cow}$ & NE \\
\hline Rubber flooring in part of the pen & yes/no & $\mathrm{NE}, \mathrm{CA}$ \\
\hline Dirty alley & yes/no & $\mathrm{NE}, \mathrm{CA}$ \\
\hline Automatic scraper & yes/no & $\mathrm{NE}$ \\
\hline Frequency of manure removal & times/d & $\mathrm{CA}$ \\
\hline \multicolumn{3}{|l|}{ Stall $^{5}$} \\
\hline Stocking density & $\%$ & $\mathrm{NE}, \mathrm{CA}$ \\
\hline Width $^{6}$ & $\mathrm{~cm}$ & $\mathrm{NE}, \mathrm{CA}$ \\
\hline Neck rail height ${ }^{6}$ & $\mathrm{~cm}$ & NE, CA \\
\hline Neck rail distance to the rear curb $^{6}$ & $\mathrm{~cm}$ & $\mathrm{NE}, \mathrm{CA}$ \\
\hline Adjustable neck rail & yes/no & $\mathrm{CA}$ \\
\hline Brisket locator & yes/no & $\mathrm{NE}$ \\
\hline \multicolumn{3}{|l|}{ Bedding $^{5}$} \\
\hline Deep bedding & yes/no & $\mathrm{NE}$ \\
\hline Sand bedding & yes/no & $\mathrm{NE}$ \\
\hline Sawdust bedding & yes/no & $\mathrm{NE}$ \\
\hline Bedding $\mathrm{DM}^{7}$ & $\%$ & $\mathrm{NE}, \mathrm{CA}$ \\
\hline \multicolumn{3}{|c|}{ Percentage of stalls with fecal contamination (before milking) ${ }^{7}$} \\
\hline Feed and water ${ }^{5}$ & $\%$ & $\mathrm{NE}, \mathrm{CA}$ \\
\hline Feed bunk space & $\mathrm{cm} / \mathrm{cow}$ & $\mathrm{NE}, \mathrm{CA}$ \\
\hline Feeding frequency & one or more times/d & $\mathrm{NE}, \mathrm{CA}$ \\
\hline Feed push-up frequency & times/d & $\mathrm{NE}, \mathrm{CA}$ \\
\hline Water space & $\mathrm{cm} / \mathrm{cow}$ & NE, CA \\
\hline \multicolumn{3}{|l|}{ Milking ${ }^{5}$} \\
\hline Time away from the pen for milking & $\min / \mathrm{d}$ & $\mathrm{NE}, \mathrm{CA}$ \\
\hline Distance walked for milking & $\mathrm{m} / \mathrm{d}$ & $\mathrm{NE}, \mathrm{CA}$ \\
\hline
\end{tabular}

${ }^{1}$ Units and categories are shown for continuous and categorical variables, respectively.

${ }^{2}$ Average of the $38 \pm 2$ focal cows assessed for lying behavior.

${ }^{3}$ Percentage of the high-production group.

${ }^{4}$ Average of the $3 \mathrm{~d}$ when lying behavior was recorded.

${ }^{5}$ High-production group assessed.

${ }^{6} \mathrm{n}=3$ to 7 stalls/pen.

${ }^{7} \mathrm{n}=10$ stalls $/$ pen.

al. (2010). On average, $38 \pm 2$ cows, ranging from 32 to 40 across all herds, had usable data; missing data were due to logger malfunction or cows being moved out of the assessment pen during the assessment period. Individual daily lying times, frequency of lying bouts, and lying bout duration were calculated and averaged across cows to obtain 1 value per farm. The SD of lying times among cows within each herd was also calculated as a measure of within-herd variability.

Production Measures. Lactation number and DIM of the focal cows were compiled from herd records and averaged as 1 value per farm. The mean lactation of the focal cows was [(mean $\pm \mathrm{SD}$ (range)] $2.8 \pm 0.4$ (1.6-3.6) in NE and 3.1 $\pm 0.5(2.0-4.3)$ in CA, and the mean DIM was $143 \pm 42(68-241)$ in NE and $132 \pm 37$ (69-218) in CA.

Lameness Assessment. All cows in the pen (i.e., not only the 40 focal cows described above) were gait scored as they exited the parlor using the 5-point $\mathrm{Nu}$ merical Rating System (NRS), where $1=$ sound and 5 $=$ severely lame (Flower and Weary, 2006; Chapinal et al., 2009). Cows with NRS $\geq 3$ were considered clinically lame, and cows with NRS $\geq 4$ were considered severely lame. The percentage of clinically and severely lame cows within the assessment pen was calculated for each farm. Operational challenges of working on commercial farms prevented us from assigning a specific gait score to each of the focal cows. 


\section{Facility-Based Measures}

Management and facility design measures for the herd and the assessment pen were collected using direct observation of environment and management, an interview with the herd manager during the farm visits, bedding samples, and herd records. Because of differences in management and facility design, some of the variables considered differed between regions (Table 1).

General Management. General herd and management factors included herd size (obtained from herd records), barn age (estimated by the herd manager), and THI. Air temperature and relative humidity were recorded using electronic data loggers (Hobo Temperature/Relative Humidity Data Logger, Onset Computer Corp.) contained in a solar radiation shield and fixed to a post inside the assessment pen, at 1-min intervals for $3 \mathrm{~d}(72 \mathrm{~h})$. The THI was calculated following Ravagnolo et al. (2000):

$$
\begin{aligned}
\mathrm{THI}=(1.8 \mathrm{~T} & +32)-[(0.55-0.0055 \mathrm{RH}) \\
& \times(1.8 \mathrm{~T}-26)],
\end{aligned}
$$

where $\mathrm{T}=$ air temperature $\left({ }^{\circ} \mathrm{C}\right)$ and $\mathrm{RH}=$ relative humidity (\%), and was averaged as 1 value per farm.

Pen Space and Flooring. Variables such as space per cow, type of flooring, alley cleanliness, and method of manure removal from the alleys were recorded in the assessment pen. The overall pen area $\left(\mathrm{m}^{2}\right)$, calculated as the total length $\times$ width of the pen (i.e., including stalls, alleys, and crossovers), was divided by the number of cows housed in the pen to determine the space per cow. Most farms in CA $(\mathrm{n}=33)$ allowed access to an exercise corral in addition to the freestall pen. However, access varied from farm to farm and was weather dependent, making it impossible to accurately measure effective space available; therefore, this variable was not tested for CA herds.

The majority of farms had concrete floors, with the exception of 3 farms in the NE that had rubber floors. However, some farms in both regions had rubber strips in some parts of the pen (e.g., the feeding alley); therefore, the only flooring variable considered was whether rubber flooring was present in at least a part of the pen.

The cleanliness of the alleys between the stalls was assessed before the morning milking; alleys were considered dirty if $\geq 2 \mathrm{~cm}$ of manure evenly covered the floor. In the NE, manure was removed either continuously or at a high frequency using automatic scrapers, or only a few times per day using other methods, such as flushing or skid steers. Therefore, a dichotomous variable was created for the presence of automatic scraper versus other methods with a lower frequency of manure removal. In CA, manure removal was accomplished several times per day by flushing, skid steer, or a combination of both. Given the available variation, the frequency of manure removal per day was considered in the analysis.

Stall Stocking Density and Stall Design. Stall stocking density was calculated as the number of cows per available stalls (stalls with visible barriers preventing cow use were excluded) multiplied by 100. Stall dimensions were measured on (mean $\pm \mathrm{SD}) 4 \pm 1$ stalls per pen (range $=3$ to 7 stalls, depending on the uniformity of the stall design within the pen) and included width, neck rail height from bedding, and neck rail position (calculated as the horizontal distance between the rear edge of the neck rail and the outer edge of the rear curb). These measurements were averaged to obtain 1 value per farm. Total stall length and the length from the rear curb to the brisket locator were also measured. However, the effective stall length for the cow depends on factors that affect the lunge space, such as the presence and position of the brisket locator, and whether the stalls are in a single row (facing a wall or feed alley) or double row (facing another stall, head to head). Due to variability in these factors, both within and between farms, it was not possible to develop a stall length definition that was objective and consistent across farms so this measure was not considered in the analysis. Neck rail type (i.e., stationary or adjustable in $\mathrm{CA}$; all neck rails were stationary in the NE) and presence of brisket locator (no farms had brisket locators in CA) was also recorded.

Bedding Type and Quality. In CA, all the farms had deep-bedded stalls filled with manure solids except for 4 farms that used sand; therefore, stall base and type of bedding were not considered. In the NE, there was more variability in these variables. Dichotomous variables were created for deep bedding (versus concrete, mattress, rubber mat, and so on) and the most frequent types of bedding; namely, sand and sawdust. Bedding samples were collected from 10 systematically selected stalls per pen (e.g., if there were 100 stalls in the pen, every 10th stall was sampled). Samples of approximately $50 \mathrm{~mL}$ were taken from the back one-third of each stall and pooled into 1 sample per farm for DM analysis; these samples were taken on each visit to avoid bias due to addition of fresh bedding. Samples were analyzed at Rock River Laboratory West Inc. (Visalia, CA) for CA and Dairy One Inc. (Ithaca, NY) for the NE. The same 10 stalls were also assessed for fecal contamination before milking and stall cleaning. Stalls were classified into clean and dry or containing fecal contamination. The percentage of stalls with fecal contamination was calculated for each farm.

Feed and Water. Feed bunk and water linear space was measured and divided by the number of cows in the 
pen to calculate the space per cow. Feeding practices, such as frequency of feed delivery and push-ups, were also recorded.

Milking. The daily total time cows were away from the pen for milking was calculated as the time (min) since cows left the assessment pen until the time when all cows returned to the pen (assessed during 1 milking), multiplied by milking frequency per day. The distance between the assessment pen and the milking parlor was recorded and multiplied by 2 times the milking frequency to calculate the total mandatory distance that cows walked per day due to milking.

\section{Data Analysis}

Statistical analyses were performed using SAS software (version 9.3, SAS Institute Inc., Cary, NC) considering the herd as the experimental unit. The 2 regions were analyzed separately because of large differences in management and facility design. Given the data collection protocol used for lameness (i.e., only pen-level estimates for lameness) and that our primary objective focused on the association of management and facility design factors with lying behavior, our analyses were all undertaken at the pen level. The outcomes of interest were the pen average daily lying time, SD of daily lying time, frequency of lying bouts, and average lying bout duration. Univariable analyses (PROC GLM) were first performed to assess the association between the outcome variables and each of the predictors (Table 1). All categorical predictors considered had at least 7 farms per category. Linearity between continuous predictors and outcome variables was assessed graphically and by testing the quadratic term in the model. Predictors with a univariable association of $P \leq 0.05$ were submitted to a multivariable general linear model (PROC GLM). Correlations between predictors were calculated to avoid submitting highly correlated variables $(|\mathrm{r}| \geq 0.70)$ to the same model. When 2 predictors were highly correlated, the predictor with the strongest univariable association (largest $\mathrm{R}^{2}$ ) was selected. Moreover, variance inflation factors were calculated after each model to confirm lack of multicollinearity. Multivariable models were built by manual stepwise selection. First, predictors were removed from the final model if $P>0.05$ through manual backward elimination. If the removal of a variable changed the parameter estimate of any of the remaining predictors by $>30 \%$, the variable was retained as a confounder regardless of its $P$-value (Dohoo et al., 2009). Second, eliminated predictors were reentered in the model one by one and retained if $P \leq 0.05$. Twoway interactions between the predictors that remained in the final model were tested and retained if $P \leq$ 0.05. Residuals were examined after each model to verify normality and homogeneity of variance. Outliers, high leverage points, and observations with an undue influence in the model were examined using residuals, leverage values, and Cook's distances.

\section{RESULTS}

\section{Northeastern United States}

In the $\mathrm{NE}$, the average herd lying time $( \pm \mathrm{SD})$ was $10.6 \pm 0.9 \mathrm{~h} / \mathrm{d}$, distributed in $11.8 \pm 1.8 \mathrm{bouts} / \mathrm{d}$ with an average duration of $60.3 \pm 10.1 \mathrm{~min}$. At the univariable level (Table 2), daily lying time decreased with increasing barn age and increased with the use of deep and sand bedding, bedding DM, and average DIM of the focal cows. Deep bedding was highly correlated with sand bedding $(\mathrm{r}=0.93 ; P<0.001)$ and with bedding DM $(\mathrm{r}=0.72 ; P<0.001)$; only deep bedding was submitted to the multivariable model, because it had the largest $\mathrm{R}^{2}$ at the univariable level. We also observed a tendency for a correlation between deep bedding and barn age (barns with deep bedding tending to be newer; $\mathrm{r}=-0.29 ; P=0.07)$, and barn age did not remain in the model containing deep bedding. The final model for daily lying time included deep bedding (estimate $=0.80 \pm 0.31 \mathrm{~h} / \mathrm{d} ; P=0.02$ ) and average DIM of the focal cows (estimate $=0.08 \pm 0.04 \mathrm{~h} / \mathrm{d}$ for a $10-d$ increase; $P<0.01$ ), and explained $28 \%$ of the variation $\left(\mathrm{R}^{2}=0.28\right)$.

The SD of daily lying time decreased as stall stocking density increased, and it increased with the presence of rubber flooring in part of the pen, pen space per cow, and the percentage of stalls with fecal contamination, at the univariable level. Pen space per cow was correlated with stall stocking density $(\mathrm{r}=0.70 ; P<$ 0.001 ) and was not submitted to the final model. The final model for the SD of daily lying time included stall stocking density (estimate $=-0.08 \pm 0.03 \mathrm{~h} / \mathrm{d}$ for a $10 \%$ increase; $P=0.01$ ), presence of rubber flooring in part of the pen (estimate $=0.16 \pm 0.08 ; P=0.05$ ), and percentage of stalls with fecal contamination (estimate $=0.04 \pm 0.01$ for a $10 \%$ increase; $P=0.01$ ), and explained $44 \%$ of the variation $\left(\mathrm{R}^{2}=0.44\right)$.

Frequency of lying bouts decreased and average bout duration increased with the use of deep and sand bedding, and with increasing bedding DM, at the univariable level. Because these 3 variables were highly correlated, they were not submitted to a multivariable model. Deep bedding was the variable that explained the most variation in the frequency of lying bouts $\left(\mathrm{R}^{2}\right.$ $=0.20)$ and in average bout duration $\left(\mathrm{R}^{2}=0.41\right)$. 
Table 2. Univariable associations of the herd average daily lying time (h/d), SD of lying time (h/d), frequency of lying bouts (no./d), and bout duration ( $\mathrm{min} /$ bout) with herd-level factors in the northeastern United States $(\mathrm{n}=40)^{1}$

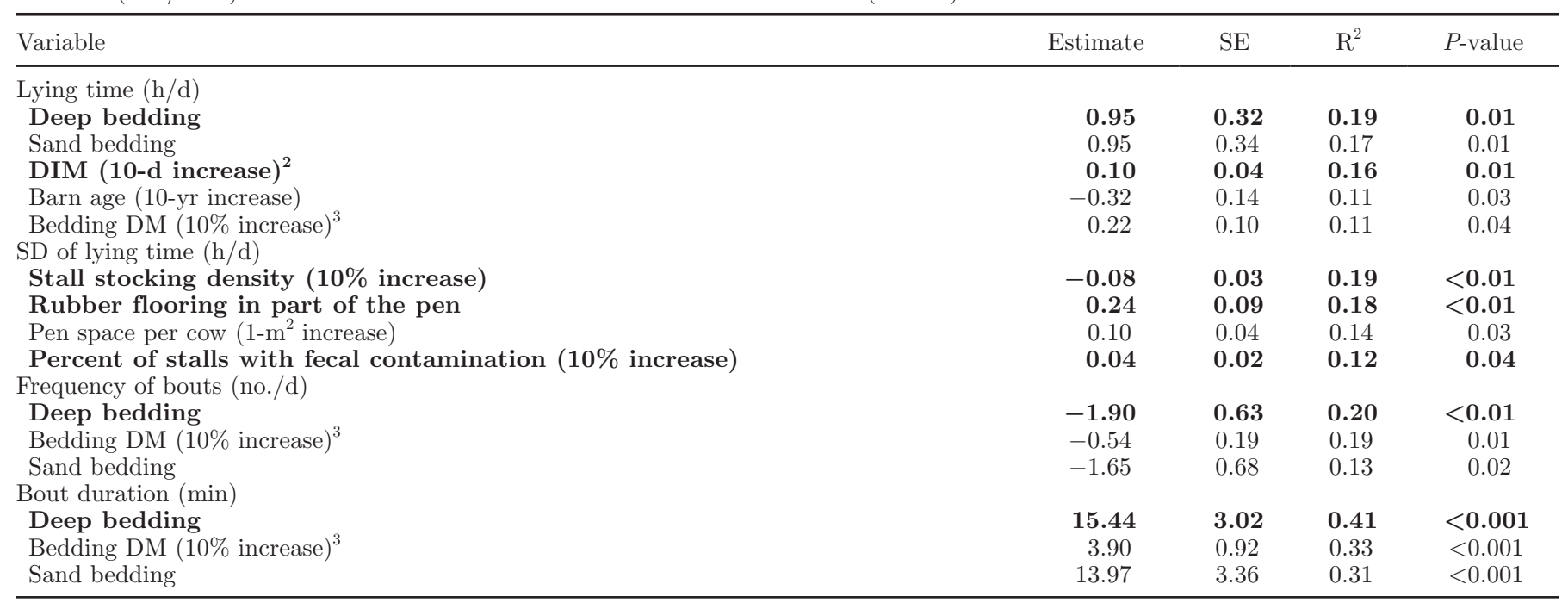

${ }^{1}$ Herd-level factors are sorted by descending $\mathrm{R}^{2}$. Bold denotes variables that remained in the final model.

${ }^{2}$ Average of the focal cows.

${ }^{3} \mathrm{n}=10$ stalls/pen, assessed before milking.

\section{California}

In CA, the herd average lying time $( \pm \mathrm{SD})$ was $10.4 \pm$ $0.7 \mathrm{~h} / \mathrm{d}$, distributed in $10.3 \pm 1.3$ bouts/d with an average duration of $65.7 \pm 8.3 \mathrm{~min}$. The average DIM of the focal group was the only predictor associated with average daily lying time at the univariable level (Table $\left.3 ; \mathrm{R}^{2}=0.16\right)$. The $\mathrm{SD}$ of daily lying time decreased when feed was delivered more than once per day. This was the only predictor associated with SD of daily lying time $\left(\mathrm{R}^{2}=0.22\right)$.

Frequency of lying bouts decreased with the percentage of stalls with fecal contamination and the percentage of severely lame cows, at the univariable level. These 2 variables were correlated $(\mathrm{r}=0.45 ; P<$
0.01), and when submitted to the same model, only the percentage of stalls with fecal contamination remained in the model $\left(\mathrm{R}^{2}=0.29\right)$.

Average bout duration decreased with the presence of rubber flooring in part of the pen, and increased with the percentage of stalls with fecal contamination and the percentage of clinically and severely lame cows, at the univariable level. The percentage of stalls with fecal contamination was correlated with the percentage of clinically $(\mathrm{r}=0.46 ; P<0.01)$ and severely $(\mathrm{r}=0.45 ; P<0.01)$ lame cows, tended to be correlated with the presence of rubber flooring in the pen $(\mathrm{r}=0.29 ; P=0.08)$, and was the only variable retained in the final model for average bout duration $\left(R^{2}=0.38\right)$.

Table 3. Univariable associations of the herd average daily lying time (h/d), SD of lying time (h/d), frequency of lying bouts (no./d), and bout duration (min/bout) with herd-level factors in California $(\mathrm{n}=39)^{1}$

\begin{tabular}{|c|c|c|c|c|}
\hline Variable & Estimate & $\mathrm{SE}$ & $\mathrm{R}^{2}$ & $P$-value \\
\hline DIM $(10-d \text { increase })^{2}$ & 0.08 & 0.03 & 0.16 & 0.01 \\
\hline \multicolumn{5}{|l|}{$\mathrm{SD}$ of lying time $(\mathrm{h} / \mathrm{d})$} \\
\hline \multicolumn{5}{|l|}{ Frequency of bouts (no./d) } \\
\hline Percent of stalls with fecal contamination $(10 \% \text { increase })^{3}$ & -0.25 & 0.06 & 0.29 & $<0.001$ \\
\hline Percent of severely lame cows ( $10 \%$ increase) & -1.33 & 0.45 & 0.19 & $<0.01$ \\
\hline \multicolumn{5}{|l|}{ Bout duration (min) } \\
\hline Percent of severely lame cows ( $10 \%$ increase) & 10.04 & 2.80 & 0.26 & $<0.01$ \\
\hline Rubber flooring in part of the pen & -5.81 & 2.57 & 0.12 & 0.03 \\
\hline Percent of clinically lame cows ( $10 \%$ increase) & 1.73 & 0.83 & 0.10 & 0.04 \\
\hline
\end{tabular}

${ }^{1}$ Herd-level factors are sorted by descending $\mathrm{R}^{2}$. Bold denotes variables that remained in the final model.

${ }^{2}$ Average of the focal cows.

${ }^{3} \mathrm{n}=10$ stalls/pen, assessed before milking. 


\section{DISCUSSION}

This cross-sectional observational study investigated associations between lying behavior and herd-level factors in 2 regions of the United States that differed in facility design and management practices. The sampling strategy targeted high-producing cows; we suggest that adequate rest may be especially important for this cohort. The high-production group typically consisted of multiparous cows in early to mid lactation, which is when the effects of inappropriate facilities and management on health problems such as lameness are most likely to surface (Espejo and Endres, 2007; Chapinal et al., 2013).

\section{Northeastern United States}

Deep bedding, sand bedding, and bedding DM content were associated with higher daily lying times and less frequent, longer bouts at the univariable level. As in other observational studies (Cook et al., 2004; Espejo et al., 2006; Gomez and Cook, 2010), the quantity of bedding was correlated with the bedding material; in the case of the current study, most of the deep-bedded stalls in the NE had sand bedding. In turn, sand had higher DM content than organic materials such as sawdust. The variability in bedding material is dependent on geographical factors, which makes it difficult to study the interaction between bedding quantity and type in observational studies. In the current study, deep bedding was the bedding factor with the strongest association with lying behavior. The use of deep bedding increased average daily lying time by $48 \mathrm{~min} / \mathrm{d}$ (or 0.8 $\mathrm{h} / \mathrm{d}$ ), after controlling for the average DIM of the focal group. This is in agreement with previous research, which shows that deep-bedded stalls (including those with at least $5 \mathrm{~cm}$ of sand on top of mattress) promote lying time (Tucker et al., 2003; Gomez and Cook, 2010), as cows prefer lying surfaces with ample bedding (Tucker and Weary, 2004; Drissler et al., 2005; Tucker et al., 2009).

The increase in daily lying time due to deep bedding was accompanied by fewer bouts of longer duration. This agrees with the findings of Gomez and Cook (2010), who reported that cows on sand stalls (deepbedded or with at least $5 \mathrm{~cm}$ of sand) had increased lying time (12.7 vs. $11.5 \mathrm{~h} / \mathrm{d})$ with fewer bouts (10.2 vs. 14.4 bouts/d) and longer bout duration (1.3 vs. 1.0 h/bout) compared with cows on mattresses. Previous studies suggest that longer duration of lying bouts is indicative of comfort while lying down (Tucker et al., 2004; Gomez and Cook, 2010). Overall, these results suggest that deep bedding provides a more comfortable lying surface for cows.
Barn age was associated with reduced daily lying time at the univariable level. There are likely commonalities among older barns such as shorter stalls, older types of stall bases, and poor ventilation that can interfere with lying behavior. In this study, deep bedding tended to be associated with newer barns, and barn age did not remain in the final model containing deep bedding, suggesting that most of the variability of lying behavior explained by barn age was explained by deep bedding.

The SD of lying time provides a measure of the variability of lying times among individual cows within herd. Individual cows show different lying patterns depending partly on factors such as health status and stage of lactation (e.g., Chapinal et al., 2009; Cyples et al., 2012; Vasseur et al., 2012). The high-production group typically consists of cows with a range of health conditions and production levels and thus, the variation in lying times within group is not surprising (Ito et al., 2009). The present data show that facility design and management are also associated with this variation.

The SD of lying time decreased as stall stocking density increased and, to a lesser extent, when pen space per cow decreased, indicating that cows show more uniform lying behavior when space is limited. To our knowledge, ours is the first study to describe this relationship; previous studies on the effect of stocking density or space allowance on lying behavior reported averages, but not variation among animals. We propose that improved access to space may allow individual cows to behave according to their preferred behavioral patterns and that competition due to limited space may restrict this behavioral flexibility; more work is needed to fully understand the effects of competition on these measures. The amount of standing and walking space in the alley may also increase options for other activities (e.g., social contact) and the ability for each cow to move freely in the pen. Telezhenko et al. (2012) showed that cows were more active in larger pens (by area) stocked at lower densities.

The presence of rubber flooring in at least part of the pen (e.g., feed alley) was associated with increased SD of lying time. Lying behavior is influenced by alternative options; for instance, cows on pasture have different behavioral patterns compared with cows in freestalls (Hernandez-Mendo et al., 2007), possibly due to the availability of space, activities, and a good quality standing surface. Tucker et al. (2006) showed that providing rubber flooring in front of the feed bunk altered standing behavior such that cows stood more frequently in front of the feed bunk and moved around the pen more. Again, having more suitable options for activity may increase the flexibility in individuals' behavioral patterns. 
The percentage of stalls with fecal contamination was associated with increased SD of lying time. The relationship between stall cleanliness and lying behavior is likely bidirectional. Cows may avoid wet, dirty stalls, but well-used stalls are also dirtier and likely less dry; for instance, stalls with a less restrictive neck rail are used more and have more manure on the surface (Tucker et al., 2005; Fregonesi et al., 2009). Factors that promote increased variation in lying time may also increase stall use and subsequent contamination of the stalls; however, further understanding of the pen layout and stall use patterns throughout the pen (i.e., different rows of stalls being used differently) is required to fully explain this association.

\section{California}

All farms in CA used deep bedding; under these conditions, the average DIM of the focal group was the only factor associated with daily lying time. Daily lying time increased with DIM, as previously reported by Bewley et al. (2010) and Vasseur et al. (2012). The SD of lying time decreased when cows were fed more than once a day. Fresh feed delivery stimulates cows to go to the feed bunk, and thus interrupts the lying patterns of cows currently occupying the stalls (DeVries et al., 2005). Delivery of fresh feed may therefore reduce the flexibility in individuals' lying patterns.

The percentages of stalls with fecal contamination and of lame cows were positively correlated, and both were associated with fewer, longer bouts. Previous studies have found that lame cows have fewer (Gomez and Cook, 2010) and longer lying bouts (Chapinal et al., 2009; Ito et al., 2010). It is therefore likely that dirty stalls were a consequence of lame cows having difficulty standing up and defecating during prolonged lying bouts.

The presence of rubber flooring in at least part of the pen was associated with shorter lying bouts at the univariable level. Cows prefer to stand on rubber versus concrete (Telezhenko et al., 2007). Thus, lying bouts may have been shorter because cows had access to a more comfortable standing surface.

\section{CONCLUSIONS}

Lying behavior of high-producing dairy cows is associated with herd-level factors, including average DIM and lameness prevalence, and facility and management measures such as stall surface, rubber flooring, and space availability. In the NE, the use of deep bedding contributed to increased lying time with fewer, longer lying bouts, suggesting that deep bedding is important for creating a comfortable lying area. In CA, where all farms used deep bedding, average DIM of the focal group was the only variable associated with lying time. Longer and fewer bouts were associated with a higher percentage of stalls with fecal contamination and of lame cows. The presence of rubber flooring was also associated with shorter bouts. In the NE, the SD of lying time across cows increased with lower stall stocking density, the presence of rubber flooring, and the percentage of stalls with fecal contamination. In CA, delivering fresh feed more than once a day decreased the SD of lying time.

\section{ACKNOWLEDGMENTS}

We thank the staff and students in the University of British Columbia (UBC) Animal Welfare Program for the many useful discussions that took place throughout this project. We especially thank Alejandra Barrientos (UBC) for her contributions throughout the project, and Ed Galo, Stephanie Gable, and Mercedes VazquezAnon (Novus International Inc., St. Charles, MO) for their support in making this project successful. This project was funded by Novus International Inc. The UBC Animal Welfare Program is funded through NSERC's Industrial Research Chair program, with industry contributions from the Dairy Farmers of Canada (Ottawa, ON, Canada), Westgen Endowment Fund (Milner, BC, Canada), Zoetis (Kirkland, QC, Canada), BC Cattle Industry Development Fund (Kamloops, BC, Canada), the BC Dairy Association (Burnaby, BC, Canada), and Alberta Milk (Edmonton, AB, Canada).

\section{REFERENCES}

Barrientos, A. K., N. Chapinal, D. M. Weary, E. Galo, and M. A. G. von Keyserlingk. 2013. Hock injuries in freestall housed dairy cows in Northeastern US and California. J. Dairy Sci. 96:3758-3765.

Bewley, J. M., R. B. Boyce, J. Hockin, L. Munksgaard, S. D. Eicher, M. E. Einstein, and M. M. Schutz. 2010. Influence of milk yield, stage of lactation, and body condition on dairy cattle lying behaviour measured using an automated activity monitoring sensor. J. Dairy Res. 77:1-6.

CCAC (Canadian Council on Animal Care). 2009. CCAC guidelines on the care and use of farm animals in research, teaching and testing. CCAC, Ottawa, ON, Canada.

Chapinal, N., A. K. Barrientos, M. A. G. von Keyserlingk, E. Galo, and D. M. Weary. 2013. Herd-level risk factors for lameness in freestall farms in the northeastern United States and California. J. Dairy Sci. 96:318-328.

Chapinal, N., A. M. de Passillé, D. M. Weary, M. A. G. von Keyserlingk, and J. Rushen. 2009. Using gait score, walking speed, and lying behavior to detect hoof lesions in dairy cows. J. Dairy Sci. 92:4365-4374.

Cook, N. B., T. B. Bennett, and K. V. Nordlund. 2004. Effect of free stall surface on daily activity patterns in dairy cows with relevance to lameness prevalence. J. Dairy Sci. 87:2912-2922.

Cook, N. B., R. L. Mentink, T. B. Bennett, and K. Burgi. 2007. The effects of heat stress and lameness on time budgets of lactating dairy cows. J. Dairy Sci. 90:1674-1682.

Cyples, J. A., C. E. Fitzpatrick, K. E. Leslie, T. J. DeVries, D. B. Haley, and N. Chapinal. 2012. Short communication: The effects of 
experimentally induced Escherichia coli clinical mastitis on lying behavior of dairy cows. J. Dairy Sci. 95:2571-2575.

DeVries, T. J., M. A. G. von Keyserlingk, and K. A. Beauchemin. 2005. Frequency of feed delivery affects the behavior of lactating dairy cows. J. Dairy Sci. 88:3553-3562.

Dohoo, I., W. Martin, and H. Stryhn. 2009. Veterinary Epidemiologic Research. 2nd ed. VER Inc., Charlottetown, Prince Edward Island, Canada.

Drissler, M., M. Gaworski, C. B. Tucker, and D. M. Weary. 2005. Freestall maintenance: Effects on lying behavior of dairy cattle. J. Dairy Sci. 88:2381-2387.

Endres, M. I., and A. E. Barberg. 2007. Behavior of dairy cows in an alternative bedded-pack housing systems. J. Dairy Sci. 90:41924200.

Espejo, L. A., and M. I. Endres. 2007. Herd-level risk factors for lameness in high-producing Holstein cows housed in freestall barns. J. Dairy Sci. 90:306-314.

Espejo, L. A., M. I. Endres, and J. A. Salfer. 2006. Prevalence of lameness in high-producing Holstein cows housed in freestall barns in Minnesota. J. Dairy Sci. 89:3052-3058.

Flower, F. C., and D. M. Weary. 2006. Effect of hoof pathologies on subjective assessments of dairy cow gait. J. Dairy Sci. 89:139-146.

Fregonesi, J. A., C. B. Tucker, and D. M. Weary. 2007. Overstocking reduces lying time in dairy cows. J. Dairy Sci. 90:3349-3354.

Fresonesi, J. A., and J. D. Leaver. 2001. Behaviour, performance and health indicators of welfare for dairy cows housed in strawyard or cubicle systems. Livest. Prod. Sci. 68:205-216.

Fregonesi, J. A., M. A. G. von Keyserlingk, C. B. Tucker, D. M. Veira, and D. M. Weary. 2009. Neck-rail position in the free stall affects standing behavior and udder and stall cleanliness. J. Dairy Sci. 92:1979-1985.

Gomez, A., and N. B. Cook. 2010. Time budgets of lactating dairy cattle in commercial freestall herds. J. Dairy Sci. 93:5772-5781.

Haley, D. B., A. M. de Passillé, and J. Rushen. 2001. Assessing cow comfort: Effects of two floor types and two tie stall designs on the behaviour of lactating dairy cows. Appl. Anim. Behav. Sci. $71: 105-117$

Haley, D. B., J. Rushen, and A. M. de Passillé. 2000. Behavioural indicators of cow comfort: Activity and resting behaviour of dairy cows in two types of housing. Can. J. Anim. Sci. 80:257-263.

Hart, B. L. 1988. Biological basis of the behavior of sick animals. Neurosci. Biobehav. Rev. 12:123-137

Hernandez-Mendo, O., M. A. G. von Keyserlingk, D. M. Veira, and D. M. Weary. 2007. Effects of pasture on lameness in dairy cows. J. Dairy Sci. 90:1209-1214.

Ito, K., M. A. G. von Keyserlingk, S. J. LeBlanc, and D. M. Weary. 2010. Lying behavior as an indicator of lameness in dairy cows. J. Dairy Sci. 93:3553-3560.

Ito, K., D. M. Weary, and M. A. G. von Keyserlingk. 2009. Lying behavior: Assessing within- and between-herd variation in free-stallhoused dairy cows. J. Dairy Sci. 92:4412-4420.

Jensen, M. B., L. J. Pedersen, and L. Munksgaard. 2005. The effect of reward duration on demand functions for rest in dairy heifers and lying requirements as measured by demand functions. Appl. Anim. Behav. Sci. 90:207-217.

Johnson, R. W. 2002. The concept of sickness behavior: A brief chronological account of four key discoveries. Vet. Immunol. Immunopathol. 87:443-450.
Ledgerwood, D. N., C. Winkler, and C. B. Tucker. 2010. Evaluation of data loggers, sampling intervals, and editing techniques for measuring the lying behavior of dairy cattle. J. Dairy Sci. 93:5129-5139

Main, D. C. J., Z. E. Barker, K. A. Leach, N. J. Bell, H. R. Whay, and W. J. Browne. 2010. Sampling strategies for monitoring lameness in dairy cattle. J. Dairy Sci. 93:1970-1978.

Munksgaard, L., M. B. Jensen, L. J. Pedersen, S. W. Hansen, and L. Matthews. 2005. Quantifying behavioural priorities-Effects of time constraints on behaviour of dairy cows, Bos taurus. Appl. Anim. Behav. Sci. 92:3-14.

Munksgaard, L., and H. B. Simonsen. 1996. Behavioral and pituitary adrenal-axis responses of dairy cows to social isolation and deprivation of lying down. J. Anim. Sci. 74:769-778.

NFACC (National Farm Animal Care Council). 2009. Code of practice for the care and handling of dairy cattle. NFACC, Ottawa, ON, Canada.

Norring, M., A. Valros, and L. Munksgaard. 2012. Milk yield affects time budget of dairy cows in tie-stalls. J. Dairy Sci. 95:102-108.

Ravagnolo, O. I. Misztal, and G. Hoogenboom. 2000. Genetic component of heat stress in dairy cattle, development of heat index function. J. Dairy Sci. 83:2120-2125.

Rushen, J., D. Haley, and A. M. de Passillé. 2007. Effect of softer flooring in tie stalls on resting behavior and leg injuries of lactating cows. J. Dairy Sci. 90:3647-3651.

Telezhenko, E., L. Lidfors, and C. Bergsten. 2007. Dairy cow preference for soft or hard flooring when standing or walking. J. Dairy Sci. 90:3716-3724.

Telezhenko, E., M. A. G. von Keyserlingk, A. Talebi, and D. M. Weary. 2012. Effect of pen size, group size, and stocking density on activity in freestall-housed dairy cows. J. Dairy Sci. 95:3064-3069.

Tucker, C. B., and D. M. Weary. 2004. Bedding on geotextile mattresses: How much is needed to improve cow comfort? J. Dairy Sci. 87:2889-2895.

Tucker, C. B., D. M. Weary, A. M. de Passillé, B. Campbell, and J. Rushen. 2006. Flooring in front of the feed bunk affects feeding behavior and use of freestalls by dairy cows. J. Dairy Sci. 89:2065-2071.

Tucker, C. B., D. M. Weary, and D. Fraser. 2003. Effects of three types of free-stall surfaces on preferences and stall usage by dairy cows. J. Dairy Sci. 86:521-529.

Tucker, C. B., D. M. Weary, and D. Fraser. 2004. Free-stall dimensions: Effects on preference and stall usage. J. Dairy Sci. 87:1208-1216.

Tucker, C. B., D. M. Weary, and D. Fraser. 2005. Influence of neck-rail placement on free-stall preference, use, and cleanliness. J. Dairy Sci. 88:2730-2737.

Tucker, C. B., D. M. Weary, M. A. G. von Keyserlingk, and K. A. Beauchemin. 2009. Cow comfort in tie-stalls: Increased depth of shavings or straw bedding increases lying time. J. Dairy Sci. 92:2684-2690.

Vasseur, E., J. Rushen, D. B. Haley, and A. M. de Passillé. 2012. Sampling cows to assess lying time for on-farm animal welfare assessment. J. Dairy Sci. 95:4968-4977.

von Keyserlingk, M. A. G., A. K. Barrientos, K. Ito, E. Galo, and D. M. Weary. 2012. Benchmarking cow comfort on North American freestall dairies: Lameness, leg injuries, lying time, facility design, and management for high-producing Holstein dairy cows. J. Dairy Sci. 95:7399-7408. 